Rev Soc Esp Dolor

2014; 21(4): 230-231

\section{Esquemas de manejo de dolor postoperatorio en cirugía abdominal abierta no ginecológica en el Hospital General "Dr. Manuel Gea González"}

\section{Sr. Director:}

Se ha descrito el dolor como una causa importante de morbimortalidad en el mundo con severa repercusión biopsicosocial, funcional y financiera, por lo que se le ha considerado un problema de salud pública, en el cual se han logrado importantes avances, reduciendo la mortalidad y mejorando la funcionalidad de los pacientes, pero no se ha acompañado tratamiento adecuado del dolor y sus complicaciones $(1,2)$.

Entre las complicaciones más frecuentes del mal control del dolor están las respiratorias, principalmente en cirugías de tórax y abdomen alto hasta en un $10 \%$ secundario a cambios fisiológicos: interrupción de la actividad normal de la musculatura respiratoria e inhibición refleja de la función diafragmática, disminución de los volúmenes pulmonares, desarrollo de atelectasias y neumonías; las cardiovasculares con una incidencia hasta del $5 \%$ por: hiperactividad simpática que conduce a un aumento de frecuencia cardiaca, presión arterial media, índice cardiaco y consumo de oxígeno del miocardio, hipercoagulabilidad e hipofibrinolisis que favorecen los procesos trombóticos; las digestivas son distensión abdominal, náuseas, vómito e inhibición de la motilidad gastrointestinal con alta incidencia de íleo paralítico hasta en un $90 \%$ tras una cirugía abdominal (4). A nivel metabólico, el dolor postoperatorio incrementa la respuesta neuroendocrina al inducir un estado de hiperactividad simpática e hipotalámica, que da como resultado: hiperglucemia, glucosuria, retención hidrosalina, estimulación del sistema renina-angiotensina, oliguria, lipólisis e hipercatabolismo proteico y a nivel psicológico no debemos menospreciar los trastornos de angustia, ansiedad, miedo y aprehensión (5).

Describimos cuáles son los esquemas de manejo analgésico utilizado en pacientes postoperados de cirugía abdominal abierta no ginecológica en el Hospital General "Dr. Manuel Gea González".

Hemos revisado los expedientes de los pacientes postoperados de cirugía abdominal abierta no ginecológica y se analizaron los diferentes esquemas de tratamiento utilizado para el control del dolor postoperatorio mediato el cual corresponde de las 48 horas posteriores a la cirugía hasta la rehabilitación del paciente.
El analgésico más utilizado como analgesia postoperatoria fue el ketorolaco en un $83 \%$, paracetamol $34 \%$, como rescate analgésico se utiliza el tramadol en un $12 \%$ de las veces. La combinación de fármacos más utilizada es el ketorolaco/paracetamol en un $21 \%$ y ketorolaco y otro AINE en un $18 \%$. Los opioides fuertes se utilizan un $6 \%$ de las veces. La comorbilidad más frecuente es la HAS en un $16 \%$ y estos en tratamiento con IECAS en un $79 \%$. El promedio de días de estancia intrahospitalaria es de 7,69 días en total, con un mínimo de 3 días y máximo de 18 días.

Los esquemas utilizados para el tratamiento del dolor postoperatorio de cirugía abdominal abierta no ginecológica en el Hospital General "Dr. Manuel Gea González" están basados en los antiinflamatorios no esteroideos (AINE) principalmente el fármaco ketorolaco en un $83 \%$, no se utilizan adyuvantes y sólo un $6 \%$ de las ocasiones se utilizan un opioide fuerte como analgesia. La vía de administración más utilizada es la endovenosa en un $94 \%$, seguida por la peridural $3 \%$, y vía oral y subcutánea 2 y $1 \%$ respectivamente. El principal diagnóstico de la causa quirúrgica es la laparotomía exploradora en un $39 \%$ secundario a obstrucción intestinal por adherencias, en un $25 \%$ de las veces la causa es secundaria a apendicetomía y el $17 \%$ por colecistectomía abierta. La principal comorbilidad es la hipertensión arterial sistémica $16 \%$ y en segundo lugar la diabetes mellitus en el $10 \%$. El promedio de días de estancia intrahospitalaria postoperatoria es de 7,69 días, con el mayor tiempo de estancia de 35 días y el mejor tiempo de estancia de 3 días. Encontramos que un $4 \%$ de los expedientes se realizó interconsulta al departamento de clínica del dolor para manejo analgésico, un porcentaje bajo para el porcentaje de pacientes con dolor postoperatorio.

A pesar de los avances en el conocimiento, el dolor postoperatorio continúa siendo infratratado. El manejo del dolor postoperatorio no se lleva a cabo de manera adecuada en conformidad con los estándares internacionales.

\author{
J.L. López Franco, M.A. Salado Ávila \\ y L.A. Templos Esteban
}

División de Cuidados Paliativos y Clínica del Dolor. Hospital General Manuel Gea González. México 


\section{BIBLIOGRAFÍA}

1. North American Nursing Diagnosis Association: Diagnósticos: Clasificación 2007-2008. Madrid: Elsevier España, S.A.; 2008.

2. Chapman CR, Syrjala KL. Measurement of pain. In: Loeser JD, ed. Bonica's Management of Pain. $3^{\text {rd }}$ ed. Philadelphia: Lippincott, Williams \& Wilkins;2001. p. 311-28.
3. Santeularia V, Catala P, Merce G. Nuevas tendencias en el tratamiento del dolor postoperatorio en cirugía general y digestiva. Cir Esp 2009;86(2):63-71.

4. Guevara-López U, Covarrubias-Gómez A, Rodríguez C. Parámetros de práctica para el manejo del dolor en México. Cir Ciruj 2007;75:385-407.

5. De Kock M. Expanding our horizons: Transition of acute postoperative pain to persistent pain and establishment of chronic postsurgical pain services. Anesthesiology 2009;1:461-3. 